\title{
A ATUALIDADE DA EDUCAÇÃO FREIREANA
}

\author{
Analice Assunção de Souza Nunes ${ }^{9}$
}

\begin{abstract}
RESUMO
O presente trabalho é uma reflexão sobre a sociedade contemporânea e as dinâmicas marcantes do papel da educação segundo uma ótica emancipadora representada pelas obras de Paulo Freire. O texto propõe uma análise dos conteúdos das obras Freireanas que dialogam com as características pós-modernas da sociedade ocidental, sob as perspectiv as econômica e ambiental. Privilegia a obra inicial de Freire "Educação \& Atualidade Brasileira", de 1959. A metodologia utilizada para o trabalho foi bibliográfica e documental. Propõe uma reflexão sobre a atualidade da educação Freireana e postula a sua adoção nos dias atuais, objetivando a emancipação dos educandos e a formação de coletivos preocupados em encaminhar relações sociais que sejam justas e igualitárias, em movimentos que demandem ações sustentáv eis e solidárias.
\end{abstract}

Palavras-chave: Paulo Freire. Concepções Freireanas. Educação Emancipadora.

\section{THE TOPICALITY OF PAULO FREIRE'S EDUCATION}

\begin{abstract}
This work is a reflexion about the contemporary society and the important dynamics in the role of education, according to an emancipatory view point represented by Paulo Freire's literary works. The content of Paulo Freire's works are in dialogue with the postmodern characteristics of Western society. This work analyzes the contente of Paulo Freire's works under the economic and environmental perspectives, favoring Freire's initial work "Educação e Atualidade Brasileira", a work of 1959. The methodology used for the work was documentary and with analysis of current works that present the contemporary society. It is proposed a reflexion on Paulo Freire's work and how current his educational proposal is.
\end{abstract}

Keywords: Paulo Freire. Conceptions of Paulo Freire. Emancipatory Education.

\footnotetext{
9 Pós graduanda em PROEJA no Instituto Federal - Campus São Paulo. Graduanda em Pedagogia na Universidade Estadual de Campinas, Unicamp. Professora de Educação Artística pelo Instituto Musical de São Paulo, 1979. E-mail: analicenunes@uol.com.br
}

Revista Exitus, Santarém/PA, Vol. 7, Nº3, p. 347-373, Set/Dez 2017. 


\section{LA ACTUALIDAD DE LA EDUCACIÓN FREIREANA}

\section{RESUMEN}

Este trabajo tiene como objetiv o reflexionar sobre la sociedad contemporánea y la dinámica notables que dan forma a la función de la educación, de acuerdo con una perspectiva emancipatoria representado por las obras de Paulo Freire. El contenido de Freireanas diálogo trabaja con las características posmodernas de la sociedad occidental y el texto las analiza bajo las perspectivas económicas y ambientales, centrándose en los primeros trabajos de Freire "Educación y actualidad de Brasil" obra de 1959. La metodología utilizada para el trabajo fue documental, con el análisis de las obras actuales que presentan la sociedad contemporánea. Se propone una reflexión sobre la educación de Freire de hoy en día.

Palabras clave: Paulo Freire. Concepciones Freireanas. Educación emancipadora.

\section{INTRODUÇÃO}

Trabalhar na educação e para a educação requer uma atitude de reflexão e atualização constante. Falar de Paulo Freire é trazer concepções que se originaram em um fazer pedagógico realizado junto às classes menos favorecidas, em todas as partes do planeta, assumidas por movimentos sociais e também exercidas em sistemas públicos.

Este trabalho foi baseado numa pesquisa bibliográfica e documental que buscou refletir sobre a atualidade das obras de Paulo Freire, em especial o primeiro trabalho "Educação \& Atualidade Brasileira", elaborado como tese para o concurso à Cadeira de História e Filosofia da Educação da Escola de Belas Artes de Pernambuco, em 1959. Essa tese foi publicada como livro posteriormente em 2003 e trouxe um diagnóstico importante da Educação Brasileira. Propõe uma articulação com autores que tratam da sociedade contemporânea, como Bauman (2007), Guattari (2001) e Senett (2009). Procurou-se contextualizar as dinâmicas sociais e apresentar aspectos para a reflexão, com inserção de materiais divulgados na mídia que abordam assuntos relacionados à temática, em especial questões ligadas ao meio ambiente, como alterações climáticas e preservação do planeta. A proposta desse trabalho é identificar na obra inicial de Paulo Freire "Educação \& Atualidade Brasileira" - os elementos que viriam constituir a 
concepção Freireana de Educação. As modificações sociais e ambientais foram, posteriormente, incorporadas à perspectiva de educação freireana, contextualizando as preocupações que a educação emancipatória (Freireana) adotou, tendo em vista a degradação ambiental e social, consequência do desenvolvimento econômico e industrial adotado no país, retratado na primeira obra de Paulo Freire.

O trabalho está estruturado nos seguintes tópicos: A educação atual no Brasil, apresentando a conjuntura educacional atual; Paulo Freire e sua contribuição para a educação, explicitando o processo de construção do homem Paulo Freire e dos ideais que nortearam sua obra, refletindo especialmente sobre seu primeiro trabalho "Educação \& Atualidade Brasileira" (FREIRE, 2003); Sociedade Contemporânea, apresentando as características da sociedade atual e as dinâmicas das relações capitalistas, sob a perspectiva ambiental e econômico-social; Uma nova perspectiva para a Educação, tratando a ecologia (Pedagogia da Terra) como um norteador do processo pedagógico em abordagens de Gadotti (2001), Boff(1996, 2000 e 2013) e Guatarri (2001); o Processo de Educação Freireano, abordando como os processos de ensino e aprendizagem enunciados pela obra Freireana são constituídos e porque eles são importantes para serem utilizados na atualidade, dialogando com pensamentos de Senett (2009) e Gadotti (2001) que apresentam reflexões sobre as dinâmicas sociais atuais; Considerações finais, expõe os argumentos para a adesão aos conceitos Freireanos de Educação, cujo processo pedagógico ressalta questões como cidadania e dignidade, permite a emancipação dos educandos, favorecendo o surgimento de movimentos coletivos, associativos para que se busquem ações solidárias em movimentos sustentáveis, reconhecendo no homem a relação com seu ambiente humano e físico. 


\section{EDUCAÇÃO ATUAL NO BRASIL}

O início do Século XXI no Brasil foi marcado por um processo de renovação democrática, representado pelos governos de Luís Inácio Lula da Silva 2003/2010 e de Dilma Roussef 2011/2016, compromissados com melhorias para a classe trabalhadora e com conquistas sociais que possibilitaram ascensão de uma parcela da população antes excluída de diversos direitos sociais.

O bom desempenho da economia trouxe uma expansão de empreendimentos, aumentando a empregabilidade e gerando um movimento de confiança, resultando na melhoria da qualidade de vida da classe trabalhadora. Os benefícios sociais, oferecidos em programas nas áreas da educação e saúde, permitiram que minorias pudessem ampliar suas expectativas de qualidade de vida, com acesso a outros níveis de ensino, podendo vislumbrar, inclusive, a formação no ensino superior. Expandiu-se a oferta de educação básica, com a finalidade de universalizar a educação.

Indivíduos que não frequentaram a escola ou dela foram excluídos obtiveram a oportunidade de acesso à escolaridade, na modalidade Educação de Jovens e Adultos (EJA). O trabalho de Leite (2015) apresenta os indicadores da Educação de Jovens e Adultos no governo Dilma Rousseff e explicita as especificidades da modalidade.

Com a crise financeira mundial agravada no final dos anos de 2000, entretanto, apesar das conquistas, o modelo capitalista impôs limites para a expansão destes direitos e tem-se hoje o recrudescimento nas conquistas sociais: políticos atuando com interesses ligados ao grande empresariado e bancadas fundamentalistas articulam a extinção de direitos significativos da classe trabalhadora, que se veem prestes a perder direitos trabalhistas e previdenciários, conforme publica Sakamoto (UOL, 2016).

A educação tem perdido investimentos públicos significativos, comprometendo o desempenho e o resultado dos processos educativos. Os 
representantes eleitos aprovaram leis que limitam o investimento público, o que impacta na qualidade da educação pública. O sucateamento do setor tem proporcionado a expansão do ensino privado, ampliando a ofert a de empresas privadas do setor educacional, especialmente nos ensinos técnicos e superiores, contrariando as expectativas do movimento de profissionais da educação e o registrado na Carta Magna Brasileira, que defende o ensino público, laico e de qualidade.

\section{PAULO FREIRE E SUA CONTRIBUIÇÃO PARA A EDUCAÇÃO}

Decorridos 20 anos da morte de Paulo Freire em 1997, seu legado permanece impactante e atual. Homem de visão humanística e educador de rara sensibilidade, soube transformar a sua história e inspirar a de muita gente, com seu exemplo e trabalho. Com uma visão perspicaz, seu caminho foi marcado por muita compreensão aos seres humanos e um respeito a todas as relações. Sua trajetória foi de reconhecimento de sua história, da história de seu povo e dos povos de outras terras, que ele reconheceu serem irmãos. Homem instruído, enxergou nos mais humildes o irmão, o ser humano com quem se dispunha a ensinar e aprender.

As obras de Paulo Freire refletem a concepção de vida de um homem que se permitiu refletir, reelaborar e reescrever sua vida, tendo sempre a coragem de se perguntar e questionar, buscando sempre aprimorar seus estudos e atuação como educador. Seus relatos atestam a confiança que mantinha nos seres humanos; suas práticas foram o resultado de relações dialógicas, na busca de uma leitura crítica do mundo, onde o sujeito tenha condições de enxergar as relações de poder que permeiam seu ambiente e se libertar.

Sua obra "Educação \& Atualidade Brasileira", elaborada para a tese de concurso para cadeira de História e Filosofia da Educação na Escola de Belas Artes de Pernambuco, defendida em 1959, traz o cerne do que viriam a ser a concepção de educação sob a perspectiva Freireana. Com lucidez e clareza na escrita, Freire apresenta a contextualização da sociedade de 
então, defendendo a educação como um processo dialógico, construído a partir das experiências de vida e saberes dos educandos, fundamentada na realidade local, valorizando a cultura e as tradições comunitárias, proporcionando a criticidade e o fazer coletivo, com o pleno exercício democrático.

Sua experiência profissional no Sesi, onde atuou junto à classe trabalhadora, o marcou intensamente. Entrar em contato com a realidade sofrida daqueles trabalhadores imprimiu aos seus ideais e à sua obra, a preocupação constante em respeitar seus interlocutores, praticando a alteridade (se colocar no lugar do outro); de reconhecer no outro os seus saberes e conhecimento; o de entender as dinâmicas sociais que oprimiam aqueles trabalhadores.

Entendeu que o papel de educador seria o de respeit ar o educando, reconhecendo seus saberes e conhecimentos; de possibilitar a ressignificação dos conhecimentos dos educandos, isto é, propondo ações pedagógicas que permitissem ao educando reconhecer que ele tem saberes, que ele vive e produz cultura; vislumbrar (superar) as marcas ideológicas que estão presentes nas dinâmicas sociais, numa ação que permitisse ao educando ter consciência crítica e exercer seu papel de cidadão, refletindo e transformando sua realidade. Entendeu que a ação educativa deveria reconhecer a realidade local, seus conhecimentos e tradições comunitárias e atuar para que os educandos se tornassem críticos e atuassem coletivamente.

Freire começou sua obra analisando a formação da sociedade brasileira, constatando que a história evidenciou a nossa inexperiência democrática: sempre se assistiu as transformações no país como expectadores. Constatou que poucas vezes o povo foi mobilizado para ações de transformação, na história da formação do país, enquanto nação.

A educação, proposta por Freire, é vivenciada por um educador comprometido com uma ação pedagógica que emancipe o educando; marcada por relações dialógicas; com o educador reconhecendo no 
educando suas experiências de vida, seus saberes e conhecimento; em dinâmicas que sejam originadas da realidade do educando, de suas tradições comunitárias, valorizando sua cultura, com temas que sejam significativos para ele; implementando ações pedagógicas que propiciem ao educando a reflexão crítica de sua realidade, superando uma visão ingênua; valorizando ações coletivas e solidárias, objetivando a transformação da realidade social opressora.

A importância da obra "Educação \& Atualidade Brasileira" está na envergadura de suas análises, com o delineamento da formação do povo brasileiro, da explicitação do processo de estruturação do país enquanto nação e de nossa inexperiência democrática. A obra Freire delineia os movimentos sociais da década de 1950, defendendo uma educação que permitisse a construção de um país com a participação de todos os segmentos sociais, em que todos fossem emancipados e vislumbra uma sociedade justa e igualitária. Em 1964 as forças dominantes e elites empresariais acabaram massacrando os movimentos libertários, com a implantação de um regime de exceção, numa ditadura que durou 21 anos.

O que chama a atenção é a atualidade de suas ponderações: Freire aponta as contradições existentes no sistema capitalista e defende uma educação que emancipe os oprimidos. Ele sempre lutou para que o povo pudesse ter consciência crítica e voz, para coletivamente transformar a realidade.

Refletindo sobre o momento atual, vê-se que as dinâmicas sociais retratam os confrontos explicitados por Freire: as classes dominantes indústria, agronegócio e empresariado - num movimento repressor, tem se unido e proposto ações que limitam as conquistas sociais e sucateiam a educação.

A Educação Brasileira atende à lógica do capitalismo; propõe uma educação que forma indivíduos supostamente convencidos de estarem capacitados para o mercado de trabalho, prontos para se adequarem às ordens vigentes, sem questionarem as dinâmicas sociais. A educação 
pública tem sido negligenciada e há um movimento midiático que desqualifica as ações educativas emanadas de escolas públicas (FREITAS, 2012).

Freire, na obra "Educação \& Atualidade Brasileira", aponta princípios para a Educação: ação dialógica, organicidade da educação (contexto histórico social), práxis refletiva (ação-reflexão-ação) e criticidade (consciência crítica). Define como manifestações da inexperiência democrática: o centralismo (caracterizado por decisões emanadas de um poder central, desconectado com o periférico), verbalismo (utilização de um discurso vazio, figurativo e desconectado de ações), antidialogação (sem diálogo, monólogo, desconhecendo a possibilidade de troca com o outro), autoritarismo (sem reconhecer a autonomia e dignidade do outro) e assistencialização (amenizando o problema, sem tentar resolv e-lo de fato, usando apenas ações paliativas).

A prática educativa deve ser proposta com elementos e conteúdos que sejam da realidade do educando, que tenham significado para ele. Mais do que ler e escrever, Freire compreende que nesta dinâmica tem que estar presente o processo de conscientização, ou seja, o educando tem que se apropriar do conhecimento e ressignificar sua realidade; o educando deve vislumbrar as relações sociais opressoras e as ações para transformalas.

O papel do educador também é elucidado: "ninguém educa ninguém, como tampouco ninguém se educa a si mesmo: os homens se educam em comunhão, mediatizados pelo mundo" (FREIRE, 2006). Esta frase indica o processo freireano: o respeito e reconhecimento que o educador deve manter para com o educando, reconhecendo os saberes que ele traz, vendo nele o seu irmão. Na obra, Freire esclarece como a educação tradicional é bancária, que só deposita conhecimento no educando, crendo que ele seja um recipiente vazio de conhecimento. Seu processo se contrapõe a esta dinâmica, trazendo para a relação o diálogo, numa conversa entre seres humanos que trocam saberes e conhecimento, 
explicitando que a pedagogia libertadora tem que ser forjada com o educando, não para o educando (FREIRE, 2006).

Freire defende o direito à palavra para todos. A questão central da educação freireana está no diálogo, na dialogicidade construída na relação educador-educando; a essência da educação como prática da liberdade. Evidencia, então, os temas geradores: são percepções da realidade do educando, o que para ele tem significado. São os temas geradores que possibilitam o processo de ressignificação da realidade e da sua apreensão consciente; o educando, ao se deparar com um novo entendimento de sua realidade, terá condições de tê-la consciente e superá-la (relação homem-mundo).

Freire explicita a importância da práxis reflexiva, a reflexão permanente do processo, ação-reflexão-ação (TORRES, 1987, p. 44). A elaboração do processo somente se dará com a análise do educador sobre as atividades e refletindo sobre os caminhos percorridos no processo. A construção do processo, porque em conjunto com os educandos, propõe relações dialógicas e dialéticas, sempre apresentando situações inusitadas ou incomuns. Isto é benéfico e promissor, já que a finalidade da educação freireana é questionar as relações sociais, identificar as opressões e superalas.

A atualidade das análises de Freire é inegável. A educação emancipadora é um processo que potencializa o exercício da cidadania de homens e de mulheres que tem consciência crítica, tem voz e constroem/transformam o mundo em que vivem. A ação educativa emancipadora propõe encaminhamentos de movimentos coletivos que ensejam um mundo igualitário.

\section{A SOCIEDADE CONTEMPORÂNEA}

Com o objetivo de apresentar a atualidade da concepção freireana de educação, apresentaremos alguns pensadores atuais, com os quais 
estabeleceremos algumas relações de suas obras com o pensamento de Freire: Zygmunt Bauman, (1925-2016), polonês radicado nos Estados Unidos, cuja obra mais conhecida é Tempos Líquidos. Neste texto Bauman (2007) analisa a sociedade contemporânea, discorrendo como as relações são fluidas, como tem-se que conviver com incertezas na vida pessoal e profissional. A formação e experiência de vida pouco contam para a construção das carreiras profissionais.

Uma análise apurada dos últimos 50 anos das transformações no planeta e das relações entre as várias nações demonstra o esgotamento sistemático das reservas naturais: as florestas dizimadas, as metrópoles inchadas e os bolsões de misérias que rodeiam as "ilhas" de prosperidade e abundância. Os grandes centros urbanos possuem bairros onde habitantes de alto poder aquisitivo estruturam seu habitat em condomínios com áreas imensas, totalmente planejadas e delimitadas, cercadas para não se conectarem com os "outros" - os de menor poder aquisitivo, os moradores das áreas periféricas e com infraestrutura inadequada, segundo Bauman (2007).

A economia capitalista facilita a exploração descontrolada de reservas naturais, na floresta amazônica, nos cerrados, no pantanal, na mata atlântica. Com o objetivo de se obter mais produtividade e lucro, os processos de obtenção de recursos não renováveis - minérios e petróleo, por exemplo - não levam em conta que os recursos naturais são finitos. A extração de matérias primas tem deixado como herança um ambiente totalmente degradado, por exemplo: as áreas de mineração desativadas, depois de esgotados seus reservatórios, são retratos de verdadeiras catástrofes. A recomposição de tais espaços demanda tempo e investimento financeiro, impactando os biomas envolvidos. As obras de Sebastião Salgado (1997a, 1997b,) fotógrafo brasileiro reconhecido mundialmente por retratar as condições de vida de povos excluídos, apresentam imagens estarrecedoras dos desastres naturais e sociais ocasionados por ações humanas. 
Bauman (2007) ressalta que as cidades passaram a ser vividas como territórios onde se habita momentaneamente, sem compartilhar a vida cotidiana. As relações virtuais definem o ser humano, que para estabelecelas deixa de estar vinculado ao local. A partir das conexões virtuais as pessoas podem estar em qualquer parte do mundo. Entretanto, não pertencem cultural e emocionalmente àquele espaço físico.

Nas cidades os espaços são delimitados - condomínios replicam espaços criados artificialmente, limitando a região que preserva apenas o desejável - espaços limpos, urbanizados e seguros, totalmente desvinculados das cidades problemáticas, pobres e feias. Os espaços urbanos tendem a se segmentar, com ocupações humanas distintas e de acordo com sua classe social:

(...) o espaço da camada superior geralmente está conectado a comunicação global e a uma vasta rede de intercambio, aberta a mensagens e experiências que envolvem o mundo inteiro. Na outra extremidade do espectro, redes locais segmentadas, frequentemente de base étnica, recorrem a sua identidade como recurso mais valioso para defender seus interesses e, em última instância, sua existência (CASTELLS, apud BAUMAN, 2007, p.80):

Bauman (2007) explicita também como a virtualidade alterou significativamente nossos modos de vida, como a conectividade trouxe uma outra dimensão para as relações humanas. Nossas relações de amizades estão interconectadas virtualmente, com a amplitude da rede mundial de comunicação. Não precisamos, necessariamente, estabelecer contato físico, para sermos aceitos em relações de amizade. As próprias relações afetivas se apresentam fluidas, não existe a perspectiva de se manter relações amorosas que sejam insatisfatórias. É presente a noção que se vive junto enquanto existe motivação para a relação. Com a independência financeira as motivações para as relações amorosas estão amparadas em convívio harmonioso e feliz (geralmente em curta duração). Os desgastes da vida moderna, os desequilíbrios financeiros, as mudanças profissionais são obstáculos para a manutenção de uma longa vida conjugal, no contexto da sociedade atual. 
Aliado ao acima exposto, a própria estrutura física das cidades induz a uma insegurança permanente: os estranhos (imigrantes), a compet ição para a sobrevivência profissional, o anonimato (perante um grande número de estranhos). As soluções adotadas para a habitação das elites têm sido os condomínios, que criam um mundo paralelo às cidades, totalmente desconectados com a realidade local. As elites dispõem de redes de comunicação que não as vinculam a nenhum lugar especial; podem habitar em determinado local por um período do ano e ter outras tantas casas, sem que haja um compromisso local, com a comunidade vizinha.

Os segregados (trabalhadores, imigrantes) são condenados a viver a agressividade das metrópoles em locais que Bauman (2007) chama de guetos, com pouca (ou nenhuma) infraestrutura, onde batalham por sobrevivência:

As cidades contemporâneas são, por esse motivo, os estágios ou campos de batalha em que os poderes globais e os significados e identidades teimosamente locais se encontram, se chocam, lutam e buscam um acordo satisfatório, ou apenas tolerável - um modo de convivência que, se espera, seja uma paz duradoura, mas que a regra mostra ser apenas um armistício: breves intervalos para consertar defesas rompidas e redistribuir unidades de combate. É esse confronto, e não qualquer fator isolado, que põe em movimento e orienta a dinâmica da cidade "liquido-moderna" (BAUMAN, 2007. P. 87).

Bauman (2007) identifica que as relações sociais implicam em compartilhamentos e tem esperança de que as cidades:

[...] possam ser vistas como laboratórios em que as formas de conviver com a diferença, ainda a serem aprendidas pelos habitantes de um planeta cada vez mais populosos, são a cada dia inventadas, testadas, memorizadas e assimiladas (BAUMAN, 2007, p.98).

Na esperança que relata Bauman (2007), de que as cidades possam ser palco de uma transformação social que agregue as diferenças humanas, em que o compartilhamento seja uma dinâmica social adotada, que o respeito seja implementado é a esperança que Paulo Freire também compartilha. Suas concepções de educação evidenciam este 
entendimento; acredita na emancipação dos educandos, em práticas coletivas de resoluções comunitárias, reforçando a identidade social, construída pelo respeito à diversidade. Bauman (2007), quando apresenta um retrato sombrio da sociedade contemporânea também aponta para o movimento de agregação existente, um movimento de resistência que fortalece a noção do coletivo, o senso de pertencimento, o fortalecimento do sentimento de nós, onde o indivíduo se reconheça como participante, como membro de uma comunidade. A esperança utópica que Freire aponta na educação emancipatória é a chave para enfrentar-se o mundo explicitado por Bauman (2007). As opressões devem ser enfrentadas e transformadas em relações de igualdade e de reconhecimento das peculiaridades individuais e das comunidades.

As relações virtuais e as comunicações midiáticas transformaram as relações humanas. Tornaram-se um elemento vital para a consolidação de uma sociedade em que os valores são efêmeros, os processos culturais tradicionais seguem deteriorados e as manifestações artísticas são globalizadas:

(...) claro que a informática e as telecomunicações jogam um papel importante no processo de mundialização, acelerando ritmos, generalizando articulações, abrindo novas possibilidades de dinamização das forças produtivas, criando meios rápidos, instantâneos e abrangentes de produção e reprodução material e cultural. A mesma dispersão mundial dos processos produtivos é acompanhada pelo desenvolvimento de recursos informáticos de integração, também em escala mundial, de tal modo que o mundo adquire características de uma imensa fábrica, acoplada com um vasto shopping center e colorido por uma enorme disneylândia. Tudo isso polarizado na rede de cidades globais desenhando o mapa do mundo (IANNI, 1999, p.55).

As ocupações no campo também se beneficiam do aparato tecnológico. Viver no campo não significa mais estar alheio aos confortos da vida moderna, afastado das tecnologias:

Também a sociedade agrária se urbaniza, não só em nível "físico", compreendendo arquitetura, urbanismo e planejamento, mas inclusive em nível sociocultural, psicológico, mental, imaginário. A mídia impressa e eletrônica, juntamente com rádio, televisão, 
computador, fax, telefone celular e outros recursos tornam-se cotidianos em muitos lugares do campo. Acentua-se a urbanização como modo de vida, compreendendo a secularização e a individuação (IANNI, 1999, p.63).

Quando nos deparamos com as notícias do mundo atual, tratando sobre as desordens sociais e conflitos, como a fuga de refugiados que deixam a Síria e migram para a Europa $(G 1,2016 a)$ ou atentados à civis originados por movimentos fundamentalistas, como os ocorridos na França ou no metrô na Inglaterra $(G 1,2016 b)$. Qualquer que seja a origem física desses acontecimentos, somos impactados pelas suas consequências. $O$ irmão que sofre ou passa fome em outras regiões do mundo, a alimentação que falta e a que sobra (como o problema de saúde que é a obesidade na atualidade), nos induzem a questionar a lógica capitalista que desconhece ou ignora a realidade das populações, que despreza o contexto cultural e que minimiza as degradações e devastações da natureza. Não é mais possível ignorar a realidade, não se pode mais acreditar que as mazelas dos outros não nos afetarão.

Não é fatalismo a declaração da catástrofe que o capitalismo propõe. As mudanças climáticas são uma realidade, os ciclos naturais hoje foram totalmente afetados pela ação humana. Uma declaração viva é o depoimento de populações indígenas no vídeo "Para onde foram as andorinhas?" divulgado pelo Instituto Sócio Ambiental - ISA (CORRÊA, 2015), que retrata a situação de desespero em que se encontram etnias que habitam áreas demarcadas, com suas zonas limítrofes agora tomadas por latifúndios que acabaram com a floresta e utilizam pesticidas e agrotóxicos, alterando profundamente o bioma. Como preservar a cultura, os saberes e as relações distintas, se a área é comprometida por fatores da degradação ambiental?

Ter consciência dos impactos gerados pelo capitalismo inconsequente, pelo consumismo desenfreado, pelas relações voláteis e instável da sociedade moderna é fundamental para conceber um movimento educacional que proponha questionamento, reflexões e ações, 
visando a transformação destas relações alienantes e totalmente destruidoras.

\section{UMA NOVA PERSPECTIVA PARA A EDUCAÇÃO}

Num mundo globalizado, totalmente conectado com as mais diferentes etnias, onde não há mais território inóspito ou desconhecido ao homem, o legado de Paulo Freire se faz presente nas concepções de entendimento de nossa maior casa: o planeta Terra.

Freire, na sua linguagem simples e visão aguçada, já propunha uma dinâmica em que todos fossem reconhecidos, em que todos praticassem a alteridade, em que olhassemos nossas vidas, mundos e relações como pertencentes a uma mesma comunidade, numa mesma rede, conectados e constantemente acessados por informações de todas as partes do mundo.

Mais do que ter-se a conexão, Freire nos exorta a transcender essa visão cotidiana das relações, propondo uma dinâmica que possibilite um entendimento e uma reflexão crítica sobre o mundo que nos rodeia e em que vivemos, que não é mais apenas nossa família, bairro ou comunidade, mas sim a Terra, os outros povos, a flora e a fauna.

Gadotti $(2001)$ e Boff $(1996,2000,2013)$ trazem perspectivas para o entendimento de uma educação emancipadora amparadas nos conceitos Freireanos. Os fundamentos de Educação Freireiana implicam no estabelecimento de relações dialógicas, reconhecendo os saberes e conhecimentos tradicionais que o educando traga, qualquer que seja sua origem social ou de etnia, em dinâmicas que propõem um olhar crítico sobre as relações de poder que dimensionam o viver humano no mundo, com o objetivo de instrumentalizar o educando para se tornar cidadão ativo com capacidade de enxergar e se inserir na realidade, transformando-a.

A realidade atual é marcada por um pós-capitalismo perverso, com a lógica da exploração intensa dos recursos humanos e naturais. A proposta de Educação Freireana é uma educação que potencializa ações coletivas 
para a transformação do mundo onde a humanidade respeite seus semelhantes e viva com a perspectiva de cuidar, preservar e manter todos os recursos naturais, em atividades sustentáveis com relações econômicas solidárias.

Gadotti (2001), em seu trabalho a "Pedagogia da Terra", dimensiona a riqueza das propostas educacionais inspirada nos conceitos de Freire:

Cabe à escola: amar o conhecimento como espaço de realização
humana, de alegria e de contentamento cultural; selecionar e rever
criticamente a conformação; formular hipóteses; ser criativa e
inventiva (inovar); ser provocadora de mensagens e não pura
receptora; produzir, construir e reconstruir conhecimento elaborado.
E mais: numa perspectiva emancipadora da educação, a escola
tem que fazer tudo isso em favor dos excluídos, não discriminando o
pobre. Ela não pode distribuir poder, mas pode construir e reconstruir
conhecimentos, saber, que é poder. Numa perspectiva
emancipadora da educação, a tecnologia contribui muito pouco
para a emancipação dos excluídos se não for associada ao
exercício da cidadania [...] fazem fluir o saber (não o dado, a
informação e o puro conhecimento), porque constroem sentido para
a vida das pessoas e para a humanidade e buscam, juntos, um
mundo mais justo, mas produtivo e mais saudável para todos.
(GADOTI, 2001, p. 7/8).

Destaca-se outro pensador atual: Felix Guattari (1930-1992), pensador francês, foi um revolucionário em sua vida e nos seus escritos. Contestador, sua obra propõe o entendimento de que a vida humana deve considerar as especificidades pessoais e o contexto físico e social. Guattari (2001) compreende que as relações sociais devem considerar o meio físico, a ecologia é evidenciada em seus trabalhos e apresenta como entende que devam ser consideradas as práticas sociais e individuais:

[...] a recomposição das práticas sociais e individuais que agrupa segundo três rubricas complementares - a ecologia social, a ecologia mental e a ecologia ambiental - sob a égide eticoestética de uma ecosofia (GUATARI, 2001, p.23).

Estes conceitos dialogam com as proposições Freireanas, que vinculam a vida cultural das comunidades com as ações educacionais:

[...] mais do que tudo a natureza não pode ser separada da cultura e precisamos aprender a pensar transversalmente as interações entre os

Revista Exitus, Santarém/PA, Vol. 7, N³ 3, p. 347-373, Set/Dez 2017. 
ecossistemas, mecanosferas e Universos de referências sociais e individuais (GUATARRI, 2001, p.25).

O entendimento de que as reflexões devem considerar todo o contexto cultural e abarcar o meio físico em que vivem as pessoas é evidente para Guattari (2001). Ressalta a importância de ações construídas coletivamente - práticas micropolíticas e microssociais:

[...] o ponto pragmático primordial da ecologia social seria o de fazer transitar essas sociedades capitalísticas da era da mídia em direção a uma era pós-mídia, assim entendida como uma reapropriação da mídia por uma multidão de grupos-sujeitos, capazes de geri-las numa via de ressingularização [...] A noção de interesse coletivo deveria ser ampliada a empreendimentos que a curto prazo não trazem "proveito" a ninguém, mas a longo prazo são portadores de enriquecimento processual para o conjunto da humanidade. É o conjunto do futuro da pesquisa fundamental e da arte que está aqui em causa (GUATARRI, 2001, p.46/47).

Ao final da obra propõe que os indivíduos devam se tornar a um só tempo solidários e cada vez mais diferentes (GUATARRI, 2001, p. 55), indicando que as individualidades devem ser evidenciadas e respeitadas.

As proposições de Guattari (2001) dialogam com as postuladas por Freire. As ações educativas propostas nas obras Freireanas compreendem articular para que os educandos se tornem emancipados, portadores de uma consciência crítica. Ressalta que esta emancipação deve acompanhar um entendimento de que o coletivo é uma instância construída, com a participação de outros, concebida como espaço para a consolidação de um consenso de nós, pertencentes a um território onde os diferentes possam participar e serem acolhidos com respeito e consideração, construindo um fazer coletivo.

A importância dada à singularização, no sentido do criar individual, ou seja, a manifestação individual, em contraposição às orientações e sugestões da mídia, potencializa a leitura de mundo com que Freire trata a ressignificação dos valores e compreensões que o educando tenha de sua realidade. 


\section{PROCESSO DE EDUCAÇÃO FREIREANO}

Pensar a educação para o mundo atual, onde modelos são descartáveis e as estruturas das relações são fluidas, onde o ser humano tem que viver com indefinições e inseguranças, com a flexibilidade necessária para adaptar-se ao mercado de trabalho, requer uma proposta pedagógica que forme um cidadão crítico, com capacidade de relações dialógicas, esperançoso, conectado virtual e pessoalmente com outros seres humanos, capaz de reconhecer a importância de cuidar de seu meio imediato e consciente da finitude dos recursos naturais.

A formação de um cidadão crítico demanda uma ação que possibilite ao ser humano refletir sobre o mundo e suas dinâmicas, superar a visão ingênua dos fatos e teorias e a transcender o senso comum. Ser capaz de entender e se sobrepor às tendências e modelos hegemônicos impostos e escolher como agir levando em conta seus valores, sua opção de relação com o mundo, respeitando suas inclinações e características.

O estabelecimento de relações dialógicas pressupõe que o educando se enxergue como alguém inteiro e de valor, que troca conhecimento e saberes com outros, numa relação de igualdade e horizontalidade, permeada por diálogos onde o falar e ouvir sejam momentos de inteireza, com o exercício da presença plena e da consciência permanente.

A esperança é uma condição primordial, que norteia as dinâmicas e ações, dando um sentido para o processo, indicando um caminho para que o educando vislumbre sua realização como ser humano.

As conexões virtuais são importantes para o estabelecimento de relações e de comunicações no mundo atual. Os benefícios destas conexões são vários: a rapidez das informações que são transmitidas em tempo real; a universalização dos instrumentos que permitem o acesso desta comunicação a qualquer pessoa, em quase o mundo todo e de qualquer condição social; a facilidade nos registros dos acontecimentos e sua divulgação imediata à rede de informações. 
A quantidade de informação é imensa e sua qualidade é questionável, pois o que se tem na rede de informações pode ser real ou irreal, as informações podem ser verídicas ou não. A educação pode disponibilizar ao educando, através de um processo pedagógico, a capacidade crítica para apurar as informações e validar os registros encontrados na rede virtual. As comunicações virtuais podem ser valiosas se operadas com consciência crítica.

Tão importante quanto às conexões virtuais é o contato pessoal, estabelecido com as pessoas que convivem e partilham a vida do educando.

Para ressaltar a importância do senso de nós (comunidade, apresentamos a obra de outro pensador contemporâneo: Richard Sennet (1943-), pensador americano, tem como obra principal o livro A corrosão do caráter, traz um estudo sobre as transformações que ocorreram nas vidas profissionais das pessoas, em virtude das alterações econômicas que as impactaram. Destacando a fragilidade atual na construção das carreiras profissionais, Sennett(2009) demonstra como estes fatores ocasionaram alterações no que concebemos como caráter. Suas analises apontam que todas as transformações sociais, decorrentes da movimentação econômica demandada por empresas transnacionais, poderão fortalecer a noção de pertencimento às comunidades; as opressões agregam as pessoas no compartilhamento de angústias e na busca de soluções coletivas:

Mesmo nos mercados de mão-de-obra mais flexíveis do globo, no Sudeste Asiático, está se tornando claro que geografias sociais e culturais locais contam muito para determinadas decisões de investimentos. O lugar tem poder, e a nova economia pode ser restringida por ele. Um lugar se torna uma comunidade quando as pessoas usam o pronome "nós". Falar desse jeito exige uma ligação particular, embora não local; um país pode constituir uma comunidade quando nele as pessoas traduzem crenças e valores partilhados em práticas diárias concretas [...] Uma das consequências não pretendidas do capitalismo moderno é que fortaleceu o valor do lugar, despertou o anseio de comunidade. Todas as condições emocionais que estudamos no local de trabalho animam esse desejo: as incertezas da flexibilidade; a ausência de confiança e compromisso com raízes fundas; a superficialidade do 
trabalho em equipe; acima de tudo, o espectro de não fazermos nada de nós mesmos no mundo, de não "arranjarmos um galho" com o nosso trabalho. Todas essas condições levam as pessoas a buscar outra cena de ligação e profundidade (SENNET, 2009, p.164/165).

No livro Sobre Educação (diálogos, volume 2), de Paulo Freire e Sergio Guimarães, Freire(2003) indica a potencialidade das relações virtuais e da conectividade para o processo educacional. Freire (2003) sempre postulou a adoção de mecanismos de comunicação modernos na educação, para compreender a lógica da linguagem utilizada, para apreender as relações de poder neles embutidos, para superação das mensagens padronizadas e massificadas. É na transcendência, na superação destes mecanismos que o educando poderá se libertar da hegemonia dos poderosos da comunicação, da mídia capitalista e opressora.

Apresentamos ainda a obra de Mikhail Bakhtin (1985-1975) pensador russo, que se dedicou ao estudo do desenvolvimento da linguagem e de sua aprendizagem, no início do século XX. O contexto de suas observações é a Revolução Russa, com as implicações que a teoria marxista proporia aos estudos. O grupo de intelectuais em que Bakhtin atuava contava ainda com outro pensador russo de renome - Vigotsky. As observações que efetuaram, em crianças que se alfabetizavam, ressaltou a importância da mediação para o êxito da aprendizagem. O texto para contextualizar os pensadores é obra de Moura (2012), que explicita como Bakhtin afirmou o discurso verbal:

origina-se em situação extraverbal com a qual mantem estreita e necessária relação, ou seja, não é suficiente; está asso ciado à vida, sem a qual não é possível significar-se; envolve um evento real e com ele forma uma unidade indissolúvel, absorvendo as avaliações referentes a esse evento (BAKHTIN, apud MOURA, 2012, p. 46/47).

Moura aponta princípios que Freire elenca:

distinção entre estar com o mundo e estar nele; a natural capacidade humana de travar relações com o mundo através dos atos de criação e de recriação, alfabetizado, ou não; os acréscimos do homem ao mundo natural, por meio de elaboração de representações através da realidade cultural; a construção do conhecimento como resultado das relações travadas com a realidade, cuja materialização se dá pela linguagem; esta instituída, socializada/socializadora, por meio do diálogo (MOURA, 2012, p. 75). 
As duas proposições dialogam: elas consideram o mundo cultural (vida) como um definidor das relações humanas, sendo a linguagem - o diálogo - a meio de inferência das ações e pensamentos humanos:

\begin{abstract}
A perspectiva freireana de uma proposta pedagógica que considere os acontecimentos do mundo, da vida real concreta dos sujeitos, subsídios a serem dados pela palavra viva, remete ao que afirma Bakhtin acerca da palavra como signo que reflete e refrata aspectos da realidade. Tal movimento ocorre porque à palavra é dado acumular as entoações forjadas nas relações estabelecidas entre os centros valorativos - os seres de consciência - em torno dos quais o mundo se organiza. Pela linguagem, material de desenvolvimento da consciência, no diálogo vivo, forjam-se os juízos e as concepções que atribuem significados à realidade (MOURA, 2012, p.147).
\end{abstract}

Estes dois pensadores estiveram em locais e tempos diferentes, entretanto duas obras refletem a preocupação que tiveram com a questão do ser humano e da relação que se estabelece entre eles, bem como a possibilidade de, com a mediação, as ações humanas serem emancipatórias:

Bakhtin aprofundou os estudos da linguagem, entendendo-a como propriedade intrínseca ao ser humano. Portanto, ao examinar a linguagem, ele analisa o homem. Freire, por sua vez, elabora uma proposta educativa cujos fundamentos sejam capazes de responder a indagações dos homens sobre si mesmos. Os dois estudiosos, como se vê, entendem o ser humano - quer representados em seres da ficção ou não - como indivíduos em construção na/pela linguagem. [...] quando Freire propôs que todo o processo alfabetizador tivesse início na reunião de material verbal no interior mesmo da vida cotidiana dos sujeitos, que se constitui por diversas instâncias de atuação dentro e fora da comunidade, parecia conceber a linguagem do mesmo modo que Bakhtin (2009), para quem "toda a vida da linguagem, seja qual for o seu campo de emprego (a linguagem cotidiana, a prática, a científica, a artística, etc), está impregnada de relações dialógicas" (MOURA, 2012, p. 167).

As propostas de entendimento da linguagem e de sua apreensão pelo ser humano são semelhantes; Bakhtin e Freire entendem ser as relações humanas um impulsionador, motivador da prática e desenvolvimento da linguagem, considerando o diálogo como propulsor da comunhão e integração entre os homens. 
O cuidado com o meio ambiente e a consciência da finitude dos recursos naturais é outro fator importante para a concepção de Educação Freireana. A vida humana é concebida no planeta Terra, hoje totalmente conectado. As realidades físicas $e$ as dimensões geográficas são impactadas pelo ser humano. Os ambientes são afetados por ações humanas. As degradações ambientais impactam toda a esfera terrestre. Os limites não mais existem: a polvição avança e não reconhece povos, etnias, cidades ou nações. Neste sentido, tornamo-nos todos companheiros de uma mesma casa e numa mesma viagem - a vida humana neste planeta.

Pensar globalmente e agir localmente é parte desta lógica. O cuidado com o meio ambiente é necessário para a vida humana. Buscar reconhecer os ciclos das dinâmicas naturais (clima, geografia, hidrografia e energias renováveis) é imprescindível para a manutenção da vida humana na Terra.

As obras de Freire apresentam concepção de uma educação que tem como objetivo reconhecer o educando como ser humano pleno, crítico, dialógico, com capacidade de articular ações coletivas para uma vida plena em uma sociedade justa e igualitária, respeitando e preservando o espaço em que vive.

Com o objetivo de emancipar os cidadãos, Freire propõe relações dialógicas no processo educativo, reconhecendo no educando o ser humano com experiência de vida, com conhecimentos e saberes, capacitado no exercício da leitura crítica do mundo e de suas relações de poder, ressaltando a importância do fazer coletivo, da construção de uma realidade mais justa e igualitária, trabalhando a consciência de uma realização cooperativa, em atividades de trabalho com caráter solidário e sustentável, tratando de seu ambiente com respeito e buscando a preservação dos recursos naturais.

A obra "Pedagogia da Terra" de Gadotti (2001), inspirada na concepção Freireana de Educação, destaca algumas categorias deste novo educar. O educar para o desenvolvimento sustentável: planetaridade, sustentabilidade, virtualidade, globalização e transdisciplinaridade. Gadotti 
(2001) ressalta a importância da cidadania ambiental local que se transforma em cidadania planetária e indica as condições básicas para sua realização economicamente factível, ecologicamente apropriada, socialmente justa e culturalmente equitativa, respeitosa e sem discriminação de gênero. Todas estas premissas estão articuladas no documento "Carta da Terra", elaborado em 2000 (BRASIL, 2000). A Pedagogia da Terra destaca novas formas de vida do cidadão ambiental:

\begin{abstract}
$1^{a}$ - Promoção da vida para desenvolver o sentido da existência; $2^{a}$ Equilíbrio dinâmico para desenvolver a sensibilidade social; $3^{a}$ Congruência harmônica que desenvolve a ternura e 0 estranhamento; $4^{a}$ - Ética integral, isto é, um conjunto de valores consciência ecológica- que dá sentido ao equilíbrio dinâmico e à congruência harmônica e que desenvolve a capacidade de autorealização:; $5^{a}$ - Racionalidade intuitiva que desenvolve a capacidade de atuar como um ser humano integral; $6^{a}$ Consciência planetária que desenvolve a solidariedade planetária(GUTIÉRREZ, apud GADOTI, 2001, p. 85/86).
\end{abstract}

Gadotti (2001) entende a educação como Ecopedagogia, tendo como princípio a gestão democrática - portanto de autonomia e de participação, defendendo a diversidade cultural.

\title{
CONSIDERAÇÕES FINAIS
}

As concepções de Educação de Paulo Freire são reconhecidas pela pertinência com que podem ser efetivadas no mundo atual: esclarece para que serve a educação, para quem é dirigida e para que é proposta. Apresentar as concepções de Freire para a educação tem o objetivo de amparar a reflexão sobre o fazer educativo. Estas reflexões já se achavam presentes na primeira obra de Freire "Educação \& Atualidade Brasileira".

As contradições presentes na sociedade atual são elementos primordiais para o entendimento de como a sociedade atual está afetada pelas ações humanas e sinalizam os encaminhamentos necessários para a manutenção da vida humana no planeta Terra. Neste sentido, a Pedagogia da Terra, oriunda das concepções Freireanas, pode atender as ações 
educativas que emancipem os educandos e os habilite a ações solidárias, coletivas e sustentáveis, emancipando-os.

No mundo capitalista, conectado virtualmente, com desequilíbrios ambientais, econômicos e sociais, definir-se o que se espera para o futuro é vital para conceber-se uma prática educativa.

A educação acontece em todos os lugares, o ser humano aprende e ensina em todos os ambientes (com os amigos, no trabalho, além da família e escola). Freire já postulava que ninguém se educa sozinho, ninguém vive sozinho: o movimento de aprendizagem, de conquistas, de emancipação é realizado conjuntamente com outros seres humanos, se faz no coletivo.

É a integração (eu e o outro) que permeia todas as ações humanas e que possibilita as construções humanas: as materiais e imateriais, as cidades, as moradias e as instituições como escola, família, governos. É no convívio humano que nos constituímos como seres humanos.

As ações humanas, mesmo quando individuais, afetam todos os ambientes, permeiam as comunidades e marcam o espaço físico. A consciência da interdependência permite compreender que qualquer ação humana deve ser construída coletivamente, com a compreensão dos desdobramentos sociais, econômicos e ambientais.

Precisamos aprender, ensinar e praticar as decisões comunitárias/coletivas. Precisamos entendê-las e saber como implementalas, enquanto educadores.

Os conceitos freireanos são embasados na construção coletiva do processo de ensino e aprendizagem. Quando o educador respeita e reconhece os educandos como protagonistas da ação pedagógica, o processo é concebido conjuntamente, a realidade local está presente nas dinâmicas educativas, na concepção do currículo, no reconhecimento do entorno (realidade local), das diversidades e histórias pessoais de nossos educandos (e da nossa história como educador). Todo este conjunto de elementos se consolida num grupo, num coletivo que é nossa classe, nossa realidade educacional. 
Neste processo, construído com o respeito pelo outro, pelo conjunto das diversidades que forma o coletivo, pela representação do que é a comunidade, é possível implementar uma educação que permita a apreensão de uma consciência crítica e de um fazer coletivo.

As obras de Freire propõem uma ação educativa que emancipa o educando, podendo ocorrer em vários espaços, como educação formal (nos sistemas regulares de ensino/escolas) ou como educação não formal (em associações, comunidades, organizações diversas, em qualquer outro ambiente).

Seu princípio básico é reconhecer no educando um ser humano integral, com saberes e valores; com o educador propiciando movimentos de ressignificações e apreensão da realidade, sob uma perspectiva crítica, numa construção de relações dialógicas e ressaltando ações coletivas como encaminhamentos para uma transformação da realidade, em atitudes solidárias, coletivas e sustentáveis.

Ter a compreensão das desigualdades sociais, que afligem uma parcela imensa dos habitantes de nosso planeta permite considerar que a educação deve atuar para transformar esta realidade, atuando para potencializar a criticidade de seus educandos, propondo exercícios de cidadania e construção de coletividade, com valores que reflitam o respeito ao ambiente, o cuidado com os recursos naturais e culturais, a economia sustentável e a consolidação de uma sociedade que seja justa e igualitária.

\section{REFERÊNCIAS}

BAUMAN, Z. Tempos líquidos. Rio de Janeiro, Jorge Zahar Ed.,2007.

BOFF, L. Sustentabilidade: o que é - o que não é. Petrópolis, Vozes, 2013.

BOFF, L. Saber cuidar: ética do humano: compaixão pela terra. Petrópolis, Vozes, 2000.

BOFF, L. Dignitas terrae: ecologia: grito da terra, grito dos pobres. São Paulo, Ática, 1996. 
BRASIL. Ministério do Meio Ambiente. Carta da Terra. 2000. Disponível em <http://www.mma.gov.br/estruturas/agenda21/_arquivos/carta_terra.pdf >. Acesso em 17/12/2016.

CORRÊA, M. Video: Para onde foram as andorinhas? Instituto Catitu e Instituto Socioambiental, 2016. Disponível em: <https://www.socioambiental.org/pt$\mathrm{br} /$ noticias-socioambientais/premiado-curta-lancado-para-internet-alertapara-mudancas-climaticas-no-xingu $>$. A cesso em 17/12/2016.

DOURADO, L. F. Políticas e gestão da educação no Brasil: múltiplas regulações e controle. Revista Brasileira de Política e Administração da Educação, v. 27, n. 1, p. 53-65, 2011.

FREIRE, P. R. N. Educação \& Atualidade Brasileira. São Paulo, Editora Cortez, 2003.

FREIRE, P.; GUIMARÃES, S. Sobre educação (diálogos). Volume 2, São Paulo, Editora Paz e Terra, 2003.

FREIRE, P. R. N. Pedagogia do oprimido. Rio de Janeiro, Paz e Terra, 2006.

FREITAS, L. C. de. Os reformadores empresariais da educação: da desmoralização do magistério à destruição do sistema público de Educação. Revista Educação e Sociedade, Campinas, v.33, n.119 abr.-jun. 2012.

GADOTTI, M. Pedagogia da terra: ecopedagogia e educação sustentável. In: CLACSO, Consejo Latinoamericano de Ciencias Sociales, Buenos Aires, 2001. Disponível em: <http://bibliotecavirtual.clacso.org.ar/clacso/gt/ 20101010031842/4gadotti.pdf >. Acesso em: 07 jun. 2016.

$\mathrm{G} 1$. Prefeitos europeus criam rede de ajuda aos refugiados. 2016a. Disponível em <http://gl.globo.com/mundo/noticia/prefeitos-europeus-criam-rede-deajuda-aos-refugiados.ghtml>, acesso em 17/12/2016).

G1. Franceses saem às ruas para lembrar vítimas de ataques terroristas no último ano. 2016b. Disponível em < http://gl.globo.com/mundo/noticia/prefeitos-europeus-criam-rede-deajuda-aos-refugiados.ghtml >. Acesso em 17/12/2016.

GUATTARI, F. As três ecologias. Campinas, Papirus, $1^{a}$ Edição Eletrônica, 2001. IANNI, O. A era do globalismo. Rio de Janeiro, Civilização Brasileira, 1999.

LEITE, S. F. Indicadores sobre a Educação de Jovens e Adultos no Governo Dilma Rousseff. In: VIII SEMINÁRIO DO PROGRAMA DE PÓS-GRADUAÇÃO EM EDUCAÇÃO X SEMINÁRIO DA FA CULDADE DE EDUCAÇÃO, 2015, Campinas. PRODUÇÃO DO CONHECIMENTO EM EDUCAÇÃO: Tensões da/na escola: homogênea? singular?. Campinas: PUC, 2015. v.1. p.158 - 170

MOURA, E. M. de. Leitura em Bakhtin e Paulo Freire - Palavras e mundos. São Carlos, Pedro \& João Editores, 2012. 
MOREIRA, A. F. B.; KRAMER, S. Contemporaneidade, educação e tecnologia. Educação e Sociedade, v. 28, n. 100, p. 1037-1057, 2007.

SALGADO, S. Trabalhadores: uma arqueologia da era industrial. São Paulo, Companhia das Letras, 1997a.

SALGADO, S. Terra. São Paulo, Companhia das Letras, 1997b.

SENNETT, R. A corrosão do caráter. Rio de Janeiro, Record, 2009.

TORRES, R. M. Educação Popular, um encontro com Paulo Freire. São Paulo. Edições Loyola, 1987.

UOL. Especialistas apontam os riscos aos trabalhadores em um governo Temer. Blog do Sakamoto. Disponivel em: <http://blogdosakamoto.blogosfera.vol.com.br/2016/04/25/especialistas apontam os riscos aos trabalhadores em um governo temerz. Acesso em $11 / 11 / 2016$.

Recebido em: Janeiro de 2017 Aceito em: Abril de 2017 